\title{
Gliadin Antibody Measurement
}

National Cancer Institute

\section{Source}

National Cancer Institute. Gliadin Antibody Measurement. NCI Thesaurus. Code C147347.

The determination of the amount of gliadin antibody present in a sample. 